\title{
A Case of Adult-Onset Alexander Disease Featuring Severe Atrophy of the Medulla Oblongata and Upper Cervical Cord on Magnetic Resonance Imaging
}

\author{
Tadahiro Yonezu $^{a}$ Shoichi Ito $^{\mathrm{b}}$ Kazuaki Kanai $^{\mathrm{a}}$ Saeko Masuda $^{\mathrm{a}}$ \\ Kazumoto Shibuya ${ }^{a}$ Satoshi Kuwabara ${ }^{a}$ \\ ${ }^{\mathrm{a}}$ Department of Neurology and ${ }^{\mathrm{b}}$ Office of Medical Education, Graduate School of Medicine, \\ Chiba University, Chiba, Japan
}

\section{Key Words}

Alexander disease $\cdot$ Glial fibrillary acidic protein $\cdot$ Medulla oblongata $\cdot$ MRI $\cdot$ M74T

\begin{abstract}
Adult-onset Alexander disease (AOAD) has been increasingly recognized since the identification of the glial fibrillary acidic protein gene mutation in 2001. We report on a 56year-old man who was genetically confirmed as AOAD with the glial fibrillary acidic protein mutation of p.M74T. He developed spastic tetraparesis, sensory disturbances in four limbs, and mild cognitive impairment without apparent dysarthria and dysphagia. The case was characterized by severe atrophy of the medulla oblongata and upper cervical cord with intramedullary signal intensity changes on magnetic resonance imaging. While AOAD is diverse in clinical presentation, the peculiar magnetic resonance imaging findings of marked atrophy of the medulla oblongata and cervical cord are thought to be highly suggestive of the diagnosis of AOAD.
\end{abstract}

\section{Introduction}

Alexander disease (AD) is an encephalopathy characterized by formation of astrocytic inclusions called Rosenthal fibers [1]. AD has been mainly described as the infantile form, featuring macrocephaly, motor and mental retardation, bulbar dysfunction, and seizures, and generally leads to death before the age of 10. Its juvenile form shows bulbar and pseudobulbar palsy, spastic paresis, cerebellar ataxia, and normal mental function. In recent years, adult-onset AD (AOAD) has been increasingly 
recognized since the identification of the glial fibrillary acidic protein (GFAP) gene mutation in 2001 [2, 3]. The magnetic resonance imaging (MRI) findings specific to AOAD are atrophy and signal intensity changes of the medulla oblongata and upper cervical cord, despite a well-preserved volume of the pons, which is remarkably different from infantile cases [4]. The clinical symptoms of AOAD are similar to those in the juvenile form, but the disease progression is slower, and in many cases, bulbar palsy is obvious and palatal myoclonus may occur [5].

Here, we report on an AOAD patient with the GFAP mutation of p.M74T, with severe atrophy of the medulla oblongata and upper cervical cord seen on MRI in contrast to clinically subtle bulbar palsy. Including our patient, this gene mutation has been reported only in two AOAD patients.

\section{Case Presentation}

A 56-year-old man noticed clumsiness in the use of his right limbs at the age of 51. One year after the onset, he needed help with walking because of spasticity in his legs. At another hospital, he was diagnosed with spastic paraparesis with an unknown etiology. Four years after the initial onset, he developed spastic tetraparesis and required the aid of a walker. He was referred to our hospital for investigation of the etiology of spastic tetraparesis.

Neurological examinations revealed severe spasticity and hyperreflexia of all the extremities with right-side dominance. Bilateral Babinski signs were observed and the masseter reflex was increased. Saccadic eye movement was observed in smooth pursuit and horizontal gaze-evoked nystagmus was bilaterally present. Dysarthria and dysphagia were not obvious, and palatal myoclonus was not observed. Atrophy and fasciculation of the tongue were absent. The patient complained of a distal dominant tingling sensation in his legs, but superficial sensation was normal, while deep sensation was mildly decreased in his legs. Pollakiuria and sometimes urge urinary incontinence occurred.

Blood examination revealed no particular abnormalities. Cerebrospinal fluid study results were normal. Testing using the Mini-Mental State Examination revealed mild cognitive impairment (21/28, except for writing). Short-latency somatosensory-evoked potential determined from left tibial nerve stimulation showed normal N20 latency and prolonged P37 latency (62.0 ms). Nerve conduction study results were normal.

A brain MRI study showed severe atrophy of the medulla oblongata and upper cervical cord, and T2-hyperintensity lesions were symmetrically recognized on pyramidal tracts and the hilum of the dentate nuclei (fig. 1). The pons, midbrain and cerebrum were not atrophied and there were mild and nonspecific cerebral white matter changes. Analysis of the GFAP gene disclosed a mutation of p.M74T, and the final diagnosis of AOAD was confirmed.

\section{Discussion}

Our patient presented with progressive spastic tetraparesis with right-side dominance at the age of 51 . He developed mild cognitive impairment and cerebellar ocular symptoms, while dysarthria and dysphagia were not obvious. Atrophy of the medulla oblongata and upper cervical cord on MRI was severe and similar to that of previously reported AOAD patients. The mutation of p.M74T has been reported in a middle-aged Japanese AOAD patient with dysarthria and dysphagia in 2007 [6], which both were not obvious in our patient. Though details of clinical findings differed from our case, it is thought to be rather important that both patients developed AOAD. There are reports showing a genotype-phenotype correlation $[3,7]$, whereas some reports of 
AD with the R416W GFAP mutation $[8,9]$ imply that the phenotype is influenced not only by gene mutation but also by other factors.

The diagnostic MRI criteria for 'infantile' AD have been defined by van der Knaap et al. [10] as: (1) extensive cerebral white matter changes with frontal predominance; (2) a periventricular rim with a high signal on $\mathrm{T}_{1}$-weighted images and a low signal on $\mathrm{T}_{2}$ weighted images; (3) abnormalities of the basal ganglia and thalami; (4) brain stem abnormalities, and (5) contrast enhancement of particular gray and white matter structures. Van der Knaap et al. [10] proposed that four of five of these criteria must be met for an MRI-based diagnosis of AD. After identification of the GFAP gene mutation as a cause of $A D$, however, brain MRI features of AD are classified into several types: a pure leukoencephalopathy predominant in the infantile variant and a medullary-spinal cord atrophy without leukoencephalopathy [11]. In the juvenile and adult form of AD, atrophy and signal intensity changes of the medulla oblongata and upper cervical cord on MRI have been reported as specific features $[4,12]$, though clinical presentation is diverse.

We compared the reports of previous AOAD patients whose clinical and MRI findings were described in detail with the findings of our patient. While atrophy of the medulla oblongata and upper cervical cord on MRI is present in all patients with AOAD, bulbar palsy is sometimes not obvious $[4,13]$. Neuropathological examination showed wellpreserved neurons in the hypoglossal nuclei and intramedullary roots despite severe atrophy of the medulla oblongata in an AOAD patient with bulbar palsy [14], suggesting that dysarthria and dysphagia observed in patients with AOAD was pseudobulbar palsy. In our case, although bulbar palsy was not obvious, the masseter reflex was increased pathologically, and this may imply potential pseudobulbar palsy.

Diverseness of clinical presentation in AOAD patients, even if the same GFAP mutation is present, leads to difficulties in diagnosing AOAD. On the other hand, MRI findings are almost homogeneous. We suggest that, if bulbar palsy is clinically absent or subtle, severe atrophy and signal intensity changes of the medulla oblongata and upper cervical cord on MRI are sufficient to warrant analysis to detect the GFAP gene mutation.

\section{Acknowledgements}

We thank Dr. T. Yoshida (Department of Neurology, Graduate School of Medical Science, Kyoto Prefectural University of Medicine) for his analysis of the GFAP gene. This work was supported by Alexander disease research grants received from the Intractable Disease Research Grants, Ministry of Health, Labour and Welfare of the Government of Japan. 

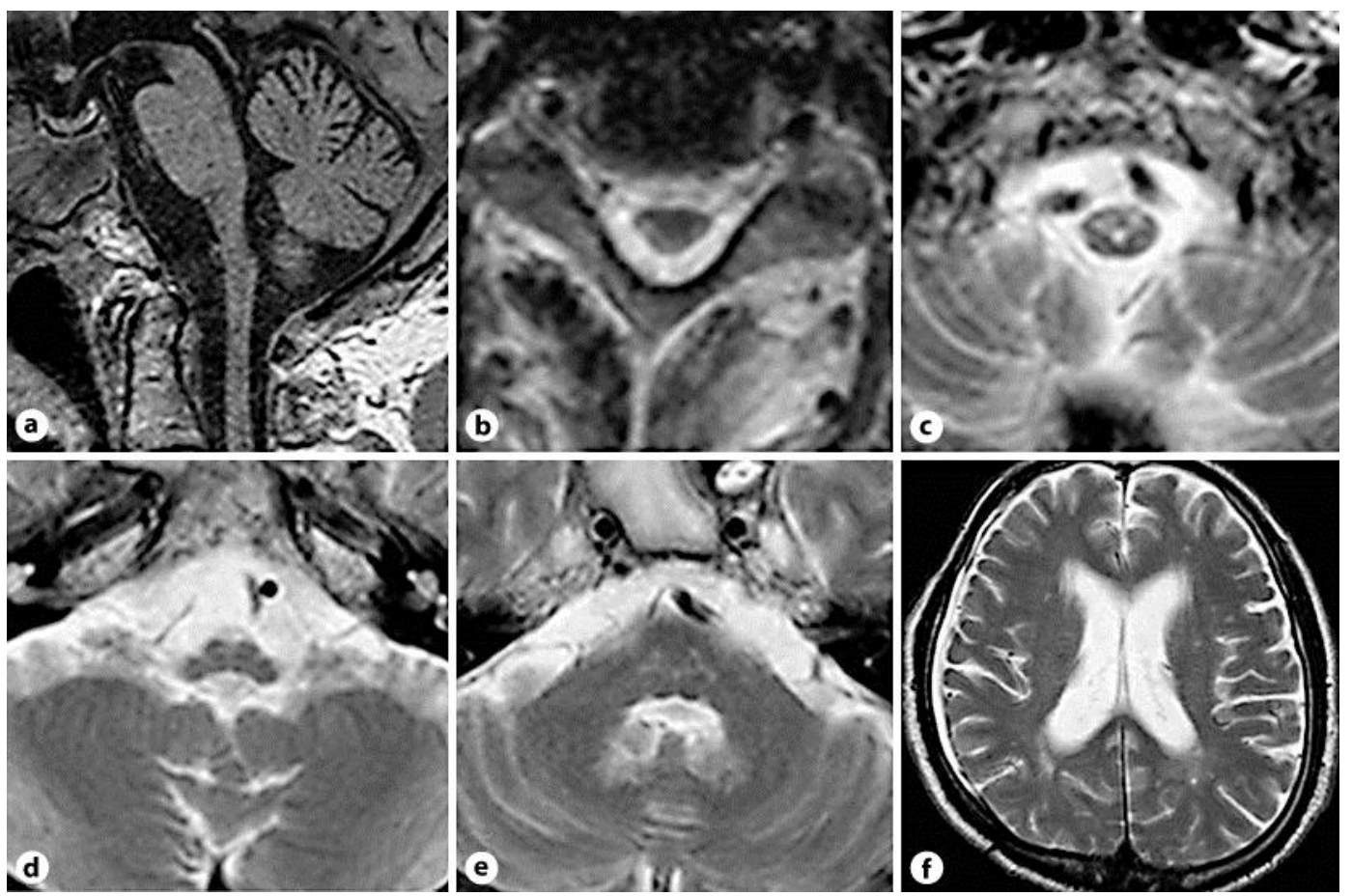

Fig. 1. a Sagittal T1-weighted images show atrophy of the medulla oblongata and upper cervical cord, while atrophy of the pons is absent. b-d There are bilateral abnormal hyperintensities in the lateral funiculus of the cervical spinal cord and the ventral medulla oblongata, which probably correspond with the pyramidal tract. e There are bilateral abnormal hyperintensities in the hilum of the dentate nuclei. f Only subtle parieto-occipital white matter lesions are seen.

\section{References}

1 Alexander WS: Progressive fibrinoid degeneration of fibrillary astrocytes associated with mental retardation in a hydrocephalic infant. Brain 1949;72:373-381.

-2 Brenner M, Johnson AB, Boespflug-Tanguy O, Rodriguez D, Goldman JE, Messing A: Mutations in GFAP, encoding glial fibrillary acidic protein, are associated with Alexander disease. Nat Genet 2001;27:117120

-3 Li R, Johnson AB, Salmons G, Goldman JE, Naidu S, Quinlan R, Cree B, Ruyle SZ, Banwell B, D’Hooghe M, Siebert JR, Rolf CM, Cox H, Reddy A, Gutierrez-Solana LG, Collins A, Weller RO, Messing A, van der Knaap MS, Brenner M: Glial fibrillary acidic protein mutations in infantile, juvenile, and adult forms of Alexander disease. Ann Neurol 2005;57:310-326.

-4 Farina L, Pareyson D, Minati L, Ceccherini I, Chiapparini L, Romano S, Gambaro P, Fancellu R, Savoiardo M: Can MR imaging diagnose adult-onset Alexander disease? Am J Neuroradiol 2008;29:1190-1196.

5 Pareyson D, Fancellu R, Mariotti C, Romano S, Salmaggi A, Carella F, Girotti F, Gattellaro G, Carriero MR, Farina L, Ceccherini I, Savoiardo M: Adult-onset Alexander disease: a series of eleven unrelated cases with review of literature. Brain 2008;131:2321-2331.

-6 Ohnari K, Yamano M, Uozumi T, Hashimoto T, Tsuji S, Nakagawa M: An adult form of Alexander disease: a novel mutation in glial fibrillary acidic protein. J Neurol 2007;254:1390-1394.

-7 Rodriguez D, Gauthier F, Bertini E, Bugiani M, Brenner M, N'guyen S, Goizet C, Gelot A, Surtees R, Pedespan J, Hernandorena X, Troncoso M, Uziel G, Messing A, Ponsot G, Pham-Dinh D, Dautigny A, Boespflug-Tanguy O: Infantile Alexander disease: spectrum of GFAP mutations and genotype-phenotype correlation. Am J Hum Genet 2001;69:1134-1140. 
8 Kinoshita T, Imaizumi T, Miura Y, Fujimoto H, Ayabe M, Shoji H, Okamoto Y, Takashima H, Osame M, Nakagawa M: A case of adult-onset Alexander disease with Arg416Trp human glial fibrillary acidic protein gene mutation. Neurosci Lett 2003;350:169-172.

-9 Thyagarajan D, Chataway T, Li R, Gai WP, Brenner M: Dominantly-inherited adult-onset leukodystrophy with palatal tremor caused by a mutation in the glial fibrillary acidic protein gene. Mov Disord 2004;19:1244-1248.

10 van der Knaap MS, Naidu S, Breiter SN, Blaser S, Stroink H, Springer S, Begeer JC, Van Coster R, Barth PG, Thomas NH, Valk J, Powers JM: Alexander disease: diagnosis with MR imaging. AJNR Am J Neuroradiol $2001 ; 22: 541-552$

11 Salvi F, Aoki Y, Della Nave R, Vella A, Pastorelli F, Scaglione C, Matsubara Y, Mascalchi M: Adult Alexander's disease without leukoencephalopathy. Ann Neurol 2005;58:813-814.

-12 van der Knaap MS, Ramesh V, Schiffmann R, Blaser S, Kyllerman M, Gholkar A, Ellison DW, van der Voorn JP, van Dooren SJM, Jacobs C, Barkhof F, Salomons GS: Ventricular garlands and abnormalities of the medulla and spinal cord. Neurology 2006;66:494-498.

13 Yoshida T, Sasayama H, Mizuta I, Okamoto Y, Yoshida M, Riku Y, Hayashi Y, Yonezu T, Takata Y, Ohnari K, Okuda S, Aiba I, Nakagawa M: Glial fibrillary acidic protein mutations in adult-onset Alexander disease: clinical features observed in 12 Japanese patients. Acta Neurol Scand 2010;124:104-108.

-14 Namekawa M, Takiyama Y, Aoki Y, Takayashiki N, Sakoe K, Shimazaki H, Taguchi T, Tanaka Y, Nishizawa M, Saito K, Matsubara Y, Nakano I: Identification of GFAP gene mutation in hereditary adult-onset Alexander disease. Ann Neurol 2002;52:779-785. 